\title{
Uniaxial Pre-strain and Free Recovery (UPFR) as a Flexible Technique for Nitinol Characterization
}

\author{
A. Cadelli ${ }^{1} \cdot$ R. M. Manjeri $^{2} \cdot$ F. Sczerzenie ${ }^{2} \cdot$ A. Coda $^{1}$
}

Published online: 23 December 2015

(c) ASM International 2015

\begin{abstract}
The measurement of phase transformation temperatures of superelastic (SE) and shape memory (SM) $\mathrm{NiTi}$ alloy products and components was studied in this work. The transformation temperatures of a set of twenty different $300 \mu \mathrm{m}$ NiTi superelastic wires were measured by two well-established and standardized techniques, namely differential scanning calorimetry (DSC) and bend and free recovery (BFR) and then compared with the results from the Uniaxial Pre-Strain and Free Recovery (UPFR) test. UPFR is a tension-based test, whose aim is to overcome the limitations associated with BFR testing. Within this work, a test procedure has been set up and validated. UPFR is found to be the only method showing a very strong correlation with the mechanical properties measured using the standard uniaxial tensile test method for superelastic NiTi alloy. Further, UPFR has been validated as a robust technique for measuring the R-phase and austenitic transformation temperatures in specimens of various sizes, composition, and of different geometries. This technique overcomes the limitations of BFR and DSC which cannot be used for testing products such as $25 \mu \mathrm{m}$ SM wire, a $50 \mu \mathrm{m}$ SE strip, and different springs and microsprings for actuation.
\end{abstract}

This article is an invited paper selected from presentations at the International Conference on Shape Memory and Superelastic Technologies 2014, held May 12-16, 2014, in Pacific Grove, California, and has been expanded from the original presentation.

A. Cadelli

andrea_cadelli@saes-group.com

$\triangle$ A. Coda

alberto_coda@saes-group.com

1 SAES Getters S.p.A., Lainate, MI, Italy

2 SAES Smart Materials, New Hartford, NY, USA
Keywords NiTi shape memory alloy - Transformation temperatures - Differential scanning calorimetry (DSC) . Bend and free recovery (BFR) - Uniaxial pre-strain and free recovery (UPFR)

\section{Introduction}

The phase transformation temperatures in NiTi shape memory alloys (SMA) can be measured by several techniques such as the differential scanning calorimetry (DSC) and the bend and free recovery (BFR). ASTM International has issued standard test methods for two techniques. F2004-05 [1] describes the method for the determination of the thermal transformation temperatures in Nickel-Titanium alloys via DSC. F2082-06 [2] defines the method for BFR and the related apparatus in order to measure the active austenite $\left(A_{\mathrm{f}}\right)$ and R-phase finish $\left(R_{\mathrm{f}}^{\prime}\right)$ transformation temperatures. The measurement of the phase transformation temperatures by BFR is limited by the techniques available to measure the sample movement during heating. Also, with the exception of materials in the fully annealed condition, the transformation finish temperatures measured by DSC and BFR differ. The reasons for such differences are not well understood. However, we observe that the DSC measures the transformation temperatures in the absence of any external stress, and the transformation temperatures may be affected by residual stress, thermal impedance of the sample geometry, and surface condition. In contrast, the BFR sample is pre-strained in a non-uniform tension and compression state and then heated to recover the strain. Each technique offers its own advantages and disadvantages. In general, the DSC is used to measure the transformation temperatures of fully annealed samples during ingot fabrication and in semi-finished mill 
products, while the BFR is used to report the transformation temperatures in both annealed and shape-set products. Despite such differences, both the techniques are often used in combination to facilitate the manufacture of a shape memory alloy product. Several studies have attempted to explore the phase transformation temperature measurements using both these techniques. For instance, Zhang et al. [3] compared the measurements in superelastic NiTi, subjected to different heat treatments. They observed discrepancies in the $A_{\mathrm{f}}$ measurements between DSC and BFR, in the presence of R-phase. Nußkern et al. [4] measured the transformation temperatures using DSC, BFR, and SFR (stretch and free recovery). They observed good correlation between BFR and SFR, under certain conditions. Nevertheless, differences between DSC and BFR/ SFR measurements were also found in their work. Wu et al. [5] performed similar studies, in addition to tensile tests. They observed that the $A_{\mathrm{f}}$ measured by BFR correlates well with the $R_{\mathrm{f}}^{\prime}$ (R-phase finish in the reverse transformation) measured by DSC. Further, the transformation temperatures measured by extrapolating the UPS (upper plateau stress)/LPS (lower plateau stress) to zero stress, using Clausius-Clapeyron relation, did not correlate with the DSC measurements. They attribute this mismatch to the fine grain structure in the samples used in their study. Thus, when it comes to measuring the phase transformation temperatures in NiTi alloys, no single technique is deemed universal. The difficulties in measuring the transformation temperature using DSC and BFR become more complicated in finer wire diameters, for example, 25- $\mu \mathrm{m}$ wires used as sensing-actuating components. In DSC, cutting and stacking an acceptable sample weight can affect the stress state and the thermal impedance of the wire in the test cell, whereas, in BFR, tracking the wire shape recovery can apply external stresses to the wire and thereby affect the transformation temperatures. Moreover, the lack of a standardized procedure for the evaluation of the functional characteristics of SMA components, especially in aerospace applications, was recently highlighted [6]. It is, therefore, the objective of the present work to establish a technique that can be used for measuring the phase transformation temperatures in shape memory alloy products/components, where the DSC or BFR procedure becomes impractical. In this regard, Uniaxial Pre-Strain and Free Recovery (UPFR) has been developed as a versatile and reliable technique for measuring the phase transformation temperatures in a wide variety of SM (shape memory) and SE (superelastic) components. The principle of UPFR is similar to BFR, where the sample is prestrained in the martensitic phase and subjected to heating. An example of the output signal along with its interpretation is provided in Fig. 1. The major advantages are (i) an easier handling of the sample, (ii) a more accurate test setup, (iii) a uniform stress state on straight samples or the possibility to test the active response of a shaped component along its working direction and (iv) a quicker turnaround time. Further, the results from this study demonstrate the feasibility of the use of UPFR across different product ranges.

\section{Experimental}

The UPFR tests were conducted on a custom-built test system, known as SMAq, shown in Fig. 2. The key components of this equipment are a linear motor, a temperature
Fig. 1 Schematic of the UPFR output and the measured transformation temperatures

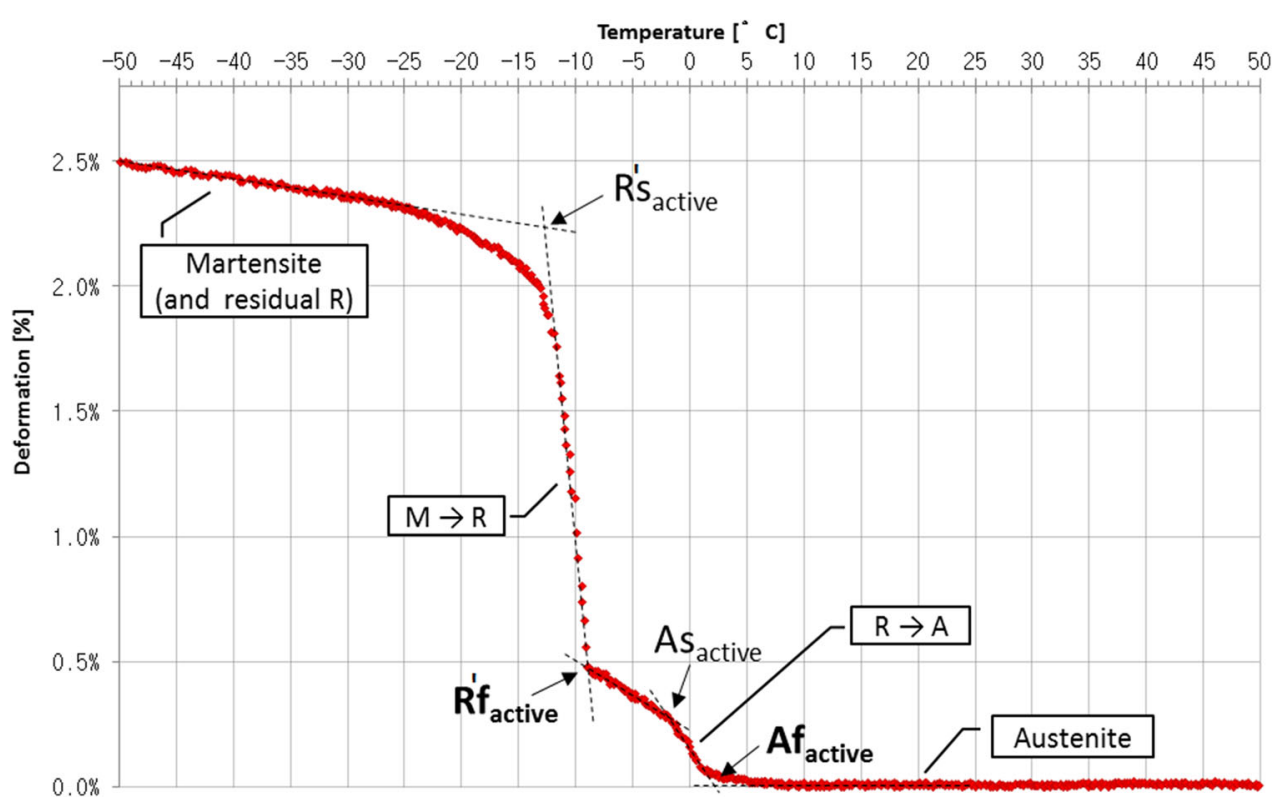


Fig. 2 The custom-built instrumental setup, SMAq, used to measure transformation temperatures in NiTi, from UPFR

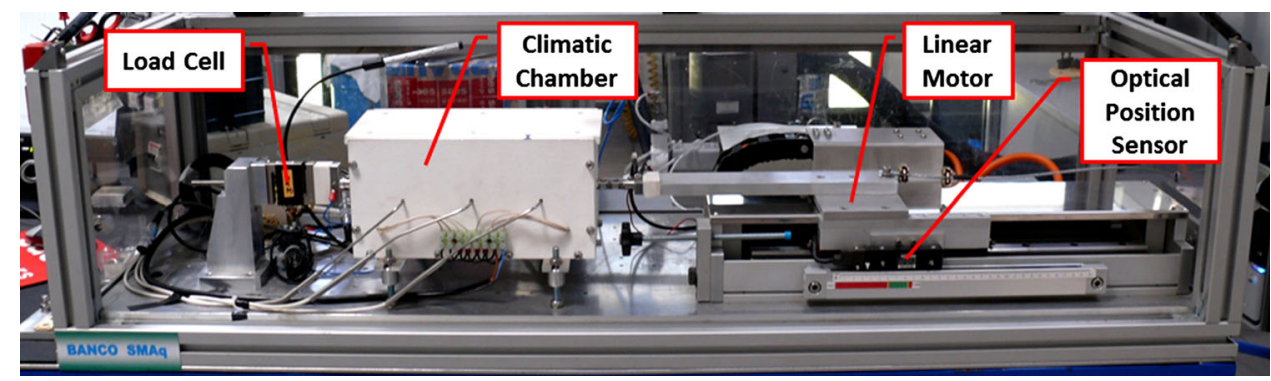

Fig. 3 DSC heating traces from different starting temperatures. The deconvolution of the two peaks reveals the R-phase peak alone, thus leading to a precise measurement of the associated temperatures

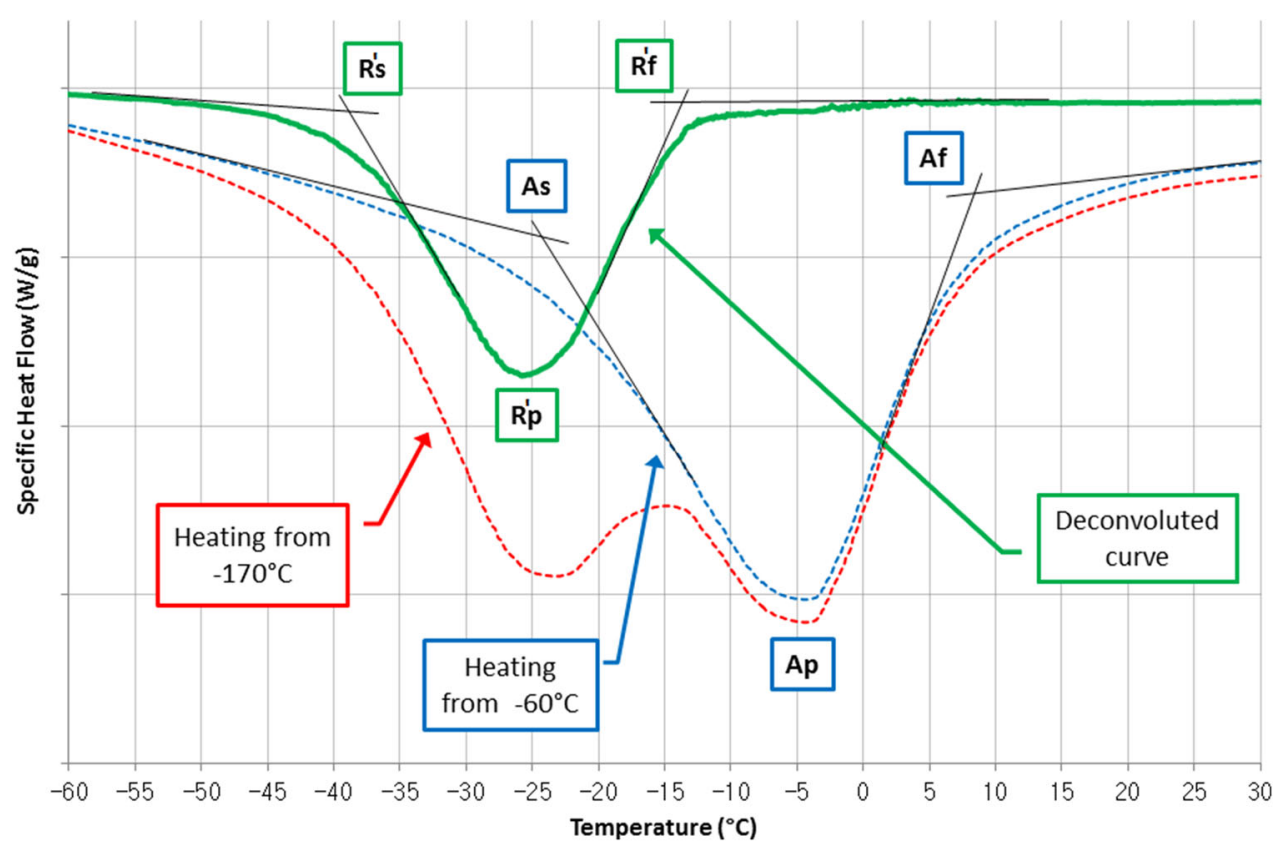

controlled chamber, a load cell, and an optical position sensor. More information on the instrument setup and its capabilities is found in Urbano et al. [7]. Although the SMAq uses a custom test bench, the UPFR test methodology is potentially applicable to any universal tensile testing equipment.

A preliminary analysis took inspiration from the work of Drexel et al. [8], with the aim to study the influence of variable starting strain on the measured transformation temperatures using the BFR. In the present work, similar studies were performed on a $300-\mu \mathrm{m}$-diameter straightannealed superelastic NiTi wires by using the UPFR. The transformation temperatures were also measured on 9 samples of $25-\mu \mathrm{m}$-diameter trained NiTi shape memory wires from a single lot of material. The robustness of the test and precision of the test results were evaluated.

In order to establish the efficiency and integrity of the test, a systematic work has been carried out. The technique was validated by testing a total of twenty $300 \mu \mathrm{m} \mathrm{NiTi}$ straight-annealed SE wires which comply with ASTM standards for biomedical-grade Nitinol products. For completeness, the twenty different wires were also tested using the DSC and the BFR. The DSC tests were carried on a TA instrument Q2000, following the protocol described for annealed samples in ASTM F2004-05 and applying the procedure shown in Fig. 3 for a precise evaluation of the R-phase peak. BFR tests were performed using a custommade system equipped with the proper LVDT sensor, following ASTM F2082-06.

The developed general test guidelines for UPFR, along with the specific test method adopted for testing the $300 \mu \mathrm{m}$ wire, are described below:

(1) The specimen is mounted on the SMAq machine at room temperature, and then, a very low constant stress is applied in load control mode. Such load is necessary to keep the specimen straight without affecting the zero length and the transformation temperatures. For example, superelastic wires are loaded with $5 \mathrm{MPa}$, obtaining a stress-induced temperature increase (ruled by the Clausius-Clapeyron equation [9]) of less than $1{ }^{\circ} \mathrm{C}$. This rule applies 
to axially aligned, non-rotating samples. Shaped components may experience localized higher shear stress. Ideally, load should be as low as possible.

(2) Temperature is stabilized below $\mathrm{M}_{\mathrm{f}}$ or the requisite minimum temperature as described in ASTM F208206, depending on the alloy composition. Sample length $\left(L_{0}\right)$ is measured.

(3) The test machine is switched to the stroke control mode and deformation is imposed with a strain rate compliant with ASTM F2516-14 [10]. For example, wires are strained to $2.5 \%$ of their initial length, springs to their operative elongation/compression setpoint.
(4) The stress is removed, and the load control mode with $5 \mathrm{MPa}$ is restored. This rule applies to axially aligned, non-rotating samples. For shaped components, load should be as low as possible.

(5) The temperature is slowly increased to keep specimen and apparatus at equilibrium. The material will start recovering the deformation at $A_{\mathrm{s}}$ (or $R_{\mathrm{s}}^{\prime}$ if $\mathrm{R}$-phase is present). For $300-\mu \mathrm{m} \mathrm{SE}$ wires, the applied heating rate was $1{ }^{\circ} \mathrm{C} / \mathrm{min}$.

(6) Results are plotted in a deformation versus temperature chart, and transformation temperatures can be determined by the tangent method. A graph of the output is shown in Fig. 1.

Table 1 Examples of different types of specimen used in the UPFR method

\begin{tabular}{|c|c|c|}
\hline Specimen & Material & Image \\
\hline $\begin{array}{c}\emptyset 25 \mu m \text { untrained round } \\
\text { wire for actuation }\end{array}$ & $\begin{array}{c}\text { Shape Memory } \\
\text { Nitinol }\end{array}$ & $1 \mathrm{~cm}$ \\
\hline $\begin{array}{c}\varnothing 100 \mu m \text { round } \\
\text { superelastic wire for } \\
\text { biomedical applications }\end{array}$ & $\begin{array}{l}\text { Biomed-grade } \\
\text { Superelastic } \\
\text { Nitinol }\end{array}$ & $1 \mathrm{~cm}$ \\
\hline $\begin{array}{c}\emptyset 300 \mu m \text { untrained round } \\
\text { wire for actuation }\end{array}$ & $\begin{array}{l}\text { Shape Memory } \\
\text { Nitinol }\end{array}$ & $1 \mathrm{~cm}$ \\
\hline $\begin{array}{c}\text { Superelastic strip } \\
\text { width } 400 \mu \mathrm{m} \\
\text { thickness } 50 \mu \mathrm{m}\end{array}$ & $\begin{array}{l}\text { Superelastic } \\
\text { Nitinol }\end{array}$ & $1 \mathrm{~cm}$ \\
\hline $\begin{array}{cc}\text { Tensile SM } & \text { micro-spring } \\
\text { OD } & 700 \mu \mathrm{m} \\
\emptyset \text { wire } & 100 \mu \mathrm{m} \\
\text { pitch } & 100 \mu \mathrm{m}\end{array}$ & $\begin{array}{l}\text { Shape Memory } \\
\text { NiTiCu }\end{array}$ & $\stackrel{1 \mathrm{~cm}}{\stackrel{2}{\longmapsto}}$ \\
\hline $\begin{array}{cc}\text { Compression SM spring } \\
\text { OD } & 13,30 \mathrm{~mm} \\
\emptyset \text { wire } & 1,50 \mathrm{~mm} \\
\text { pitch } & 6,00 \mathrm{~mm}\end{array}$ & $\begin{array}{l}\text { Shape Memory } \\
\text { Nitinol }\end{array}$ & $1 \mathrm{~cm}$ \\
\hline
\end{tabular}


The specimens were additionally evaluated by standardized tensile test method following ASTM F2516 at $37{ }^{\circ} \mathrm{C}$. Exploiting the DSC signal deconvolution method showed in Fig. 3, the ASTM procedure for BFR [10], and the above-described method for UPFR, each technique can accurately provide the martensite reversion temperature $\left(R_{\mathrm{f}}^{\prime}\right)$. In a tensile test, the reverse transformation from austenite to martensite is related to the lower plateau stress (LPS) of the superelastic curve. A relationship between LPS and $R_{\mathrm{f}}^{\prime}$ is thus expected. In order to establish the accuracy of each method, the goodness of such correlation will be evaluated.

Finally, the versatility of the technique was established by testing samples of different geometry, composition, and dimension. Table 1 enumerates the different samples tested.

\section{Results}

The results of the preliminary investigation on the effect of the pre-strain level are plotted in Fig. 4. Here, the samples were pre-strained from 1.5 to $4.5 \%$ in steps of $1 \%$, and the influence of pre-strain on the transformation temperatures was studied. The result shows a slight shift in the measured transformation temperatures with increasing pre- strain. It must, however, be emphasized that the transformation temperatures and thereby the LPS are significantly affected when the pre-strain level is high enough to introduce plastic deformation. The shift in the measured transformation temperature was between 1 and $2{ }^{\circ} \mathrm{C}$, depending on the initial strain level. The output signal obtained from the UPFR tests (i.e., the displacement measured by the tensile test bench) appears more defined than those usually obtained through the LVDT sensor in BFR. As this preliminary investigation showed how the applied pre-strain level minimally influences the outcome of the test, a test procedure has been developed applying a pre-strain equal to $2.5 \%$ of the specimen's initial austenitic length under a uniaxial stress of $5 \mathrm{MPa}$.

Measured $A_{\mathrm{f}}$ for nine $25 \mu \mathrm{m}$ SM wire specimens from the same spool are reported in Table 2. A standard deviation of $0.8^{\circ} \mathrm{C}$ confirms the reproducibility of UPFR methodology.

The results of the measurements on the $300 \mu \mathrm{m}$ SE wires are reported in Table 3 and are plotted in Fig. 5. The results show that no clear correlation is found between the values of $A_{\mathrm{f}}$ or $R_{\mathrm{f}}^{\prime}$ measured by the three different techniques. It should be noted that UPFR measures higher transformation temperatures than BFR. In a similar fashion, BFR underestimates $A_{\mathrm{f}}$ from DSC, but the same evidence is not seen for $R_{\mathrm{f}}^{\prime}$. The temperatures, and plateau
Fig. 4 Influence of varying prestrain levels on the measured finish transformation temperatures

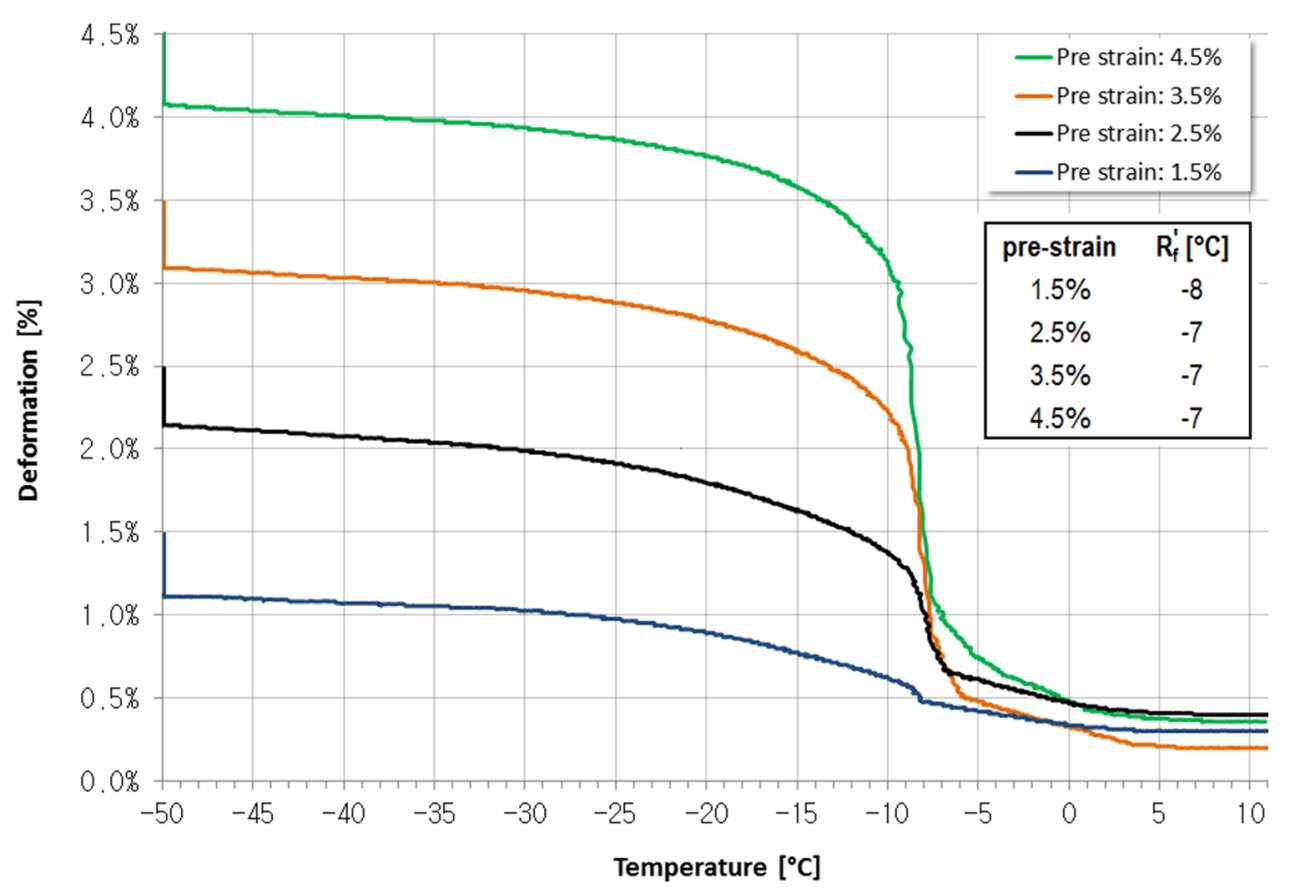

\begin{tabular}{llllllllllll}
\hline Sample \# & 1 & 2 & 3 & 4 & 5 & 6 & 7 & 8 & 9 & Average & SD \\
\hline$A_{\mathrm{f}}$ & 86.0 & 84.5 & 85.5 & 85.0 & 86.5 & 85.5 & 84.0 & 86.0 & 85.0 & 85.3 & 0.8 \\
\hline
\end{tabular}

Table $2 A_{\mathrm{f}}$ temperatures measured via UPFR on 9 samples of the same material 
Table 3 Measured mechanical and thermal properties of twenty different $300 \mu \mathrm{m}$ superelastic NiTi wires

\begin{tabular}{|c|c|c|c|c|c|c|c|c|}
\hline \multirow[t]{2}{*}{ Sample \# } & \multicolumn{2}{|c|}{ [MPa] Tensile } & \multicolumn{2}{|c|}{$\left[{ }^{\circ} \mathrm{C}\right] \mathrm{DSC}$} & \multicolumn{2}{|c|}{$\left[{ }^{\circ} \mathrm{C}\right] \mathrm{UPFR}$} & \multicolumn{2}{|c|}{$\left[{ }^{\circ} \mathrm{C}\right] \mathrm{BFR}$} \\
\hline & UPS & LPS & $R_{\mathrm{f}}^{\prime}$ & $A_{\mathrm{f}}$ & $R_{\mathrm{f}}^{\prime}$ & $A_{\mathrm{f}}$ & $R_{\mathrm{f}}^{\prime}$ & $A_{\mathrm{f}}$ \\
\hline 1 & 563 & 389 & -12 & 11 & -14 & 0 & -18 & -5 \\
\hline 2 & 549 & 353 & -8 & 13 & -10 & 7 & -13 & 1 \\
\hline 3 & 535 & 329 & -13 & 12 & -6 & 12 & -13 & 2 \\
\hline 4 & 536 & 334 & -7 & 14 & -6 & 9 & $\mathrm{n} / \mathrm{a}$ & 5 \\
\hline 5 & 529 & 327 & -7 & 11 & -4 & 13 & -8 & 0 \\
\hline 6 & 522 & 320 & -6 & 15 & -3 & 12 & -5 & 6 \\
\hline 7 & 527 & 323 & -4 & 16 & -2 & 11 & -13 & 2 \\
\hline 8 & 526 & 318 & -7 & 12 & -4 & 12 & -12 & 2 \\
\hline 9 & 520 & 303 & -5 & 12 & -3 & 13 & -12 & 3 \\
\hline 10 & 534 & 324 & -3 & 23 & -4 & 12 & -5 & 10 \\
\hline 11 & 582 & 381 & -11 & 16 & -15 & -3 & -22 & 1 \\
\hline 12 & 578 & 395 & -14 & 9 & -15 & 1 & -14 & -3 \\
\hline 13 & 581 & 398 & $\mathrm{n} / \mathrm{a}$ & 8 & -16 & 3 & -19 & -4 \\
\hline 14 & 553 & 355 & 0 & 17 & -9 & 10 & -9 & 4 \\
\hline 15 & 558 & 381 & -9 & 12 & -13 & -1 & $\mathrm{n} / \mathrm{a}$ & $\mathrm{n} / \mathrm{a}$ \\
\hline 16 & 501 & 283 & -7 & 11 & 2 & 14 & -9 & 3 \\
\hline 17 & 496 & 271 & 2 & 27 & 4 & 25 & 1 & 19 \\
\hline 18 & 547 & 354 & -16 & 10 & -9 & 7 & -16 & 2 \\
\hline 19 & 546 & 373 & -22 & 12 & -12 & 0 & -14 & -6 \\
\hline 20 & 532 & 337 & -4 & 16 & -8 & 6 & 3 & 7 \\
\hline
\end{tabular}

Results are plotted in Fig. 3

stress levels measured at $37{ }^{\circ} \mathrm{C}$ are also reported in Table 3. All samples were processed in the same way. However, many factors may impact thermo-mechanical properties including texturing, grain size and the thermomechanical history from ingot to semi-finished products. These factors are expected to affect the superelastic behavior. A systematic data analysis has been carried out and plotted in Fig. 6. The graphs show a weak and scattered correlation between LPS and $R_{\mathrm{f}}^{\prime}$ measured by either DSC $\left(R^{2}=0.30\right)$ or BFR $\left(R^{2}=0.44\right)$. In contrast, data from UPFR exhibit a good correlation with the lower plateau stress. $R_{\mathrm{f}}^{\prime}$ fits LPS with a $R^{2}=0.96$.

Figure 7 shows the phase transformation temperatures measured on a $25-\mu \mathrm{m}$-diameter NiTi shape memory wire. The nominal composition of this alloy was $\mathrm{Ni}_{49.8} \mathrm{Ti}_{50.2}$. No attempt was made to measure the phase transformation temperatures of this wire using a DSC or BFR, owing to the difficulties associated with the sample preparation and experimental setup. The measured temperature from UPFR correlates well with the desired austenite finish temperature for this wire. In a similar fashion, samples of different composition/thermo-mechanical treatment, geometry, and dimension were tested. The results are plotted in Fig. 8.

\section{Discussion}

A systematic comparison of the measured properties, especially $A_{\mathrm{f}}$ and $R_{\mathrm{f}}^{\prime}$, carried out via DSC, BFR, and UPFR on twenty $300-\mu \mathrm{m}$ NiTi straight-annealed SE wires demonstrated that each technique measures different temperatures. It is believed that the differences in the measured transformation temperatures are related to several factors such as sample preparation, externally applied stress, and thereby the starting state of the sample-twinned versus de-twinned martensite, sample geometry and residual stress in the sample. Along with the applied stress, it must be underlined that each test methodology is characterized by its own accuracy due to both the test setup and the related measuring system.

The UPFR technique has been found to show an improved sensitivity in measuring active temperatures with the respect of BFR and DSC. This has been demonstrated by comparing the measured $\mathrm{B} 19^{\prime}$ martensite-to-R-phase temperature of the three techniques $\left(R_{\mathrm{f}}^{\prime}\right)$ with the LPS (martensite reversion). UPFR is able to determine an active temperature which is linearly correlated with the plateau stress, while such correlation, although noticeable, is
Fig. 5 Comparison of the austenitic finish $\left(A_{\mathrm{f}}\right)$ and $\mathrm{R}$ phase finish $\left(R_{\mathrm{f}}^{\prime}\right)$ transformation temperatures measured using DSC, BFR, and UPFR. The data were collected from a $300-\mu \mathrm{m}$ superelastic NiTi formulation manufactured from different melt sources and subjected to varying thermo-mechanical treatments
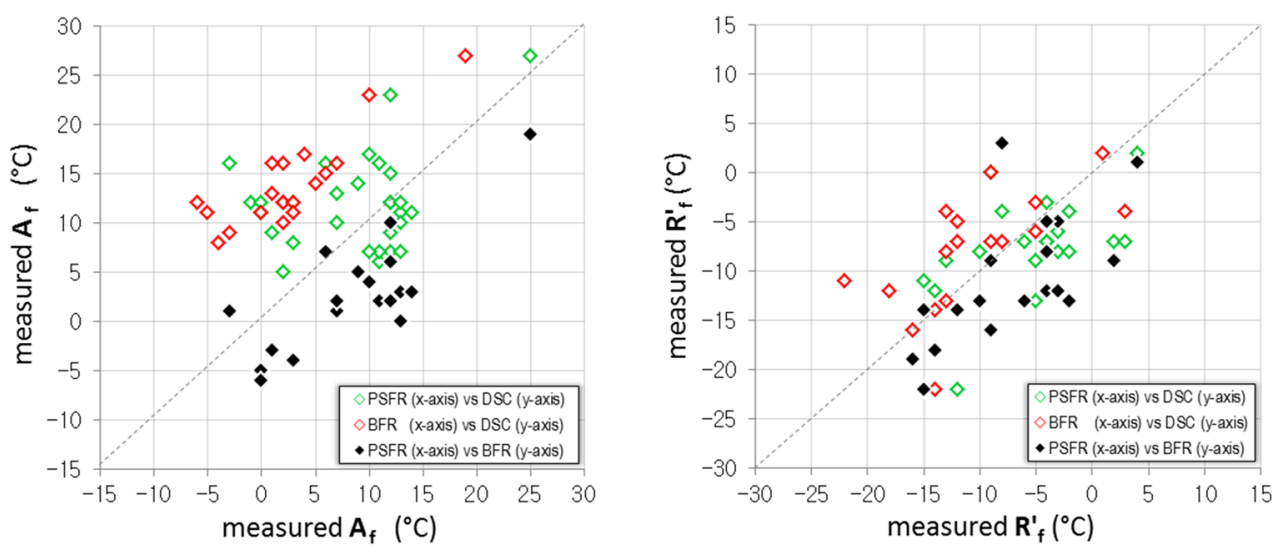

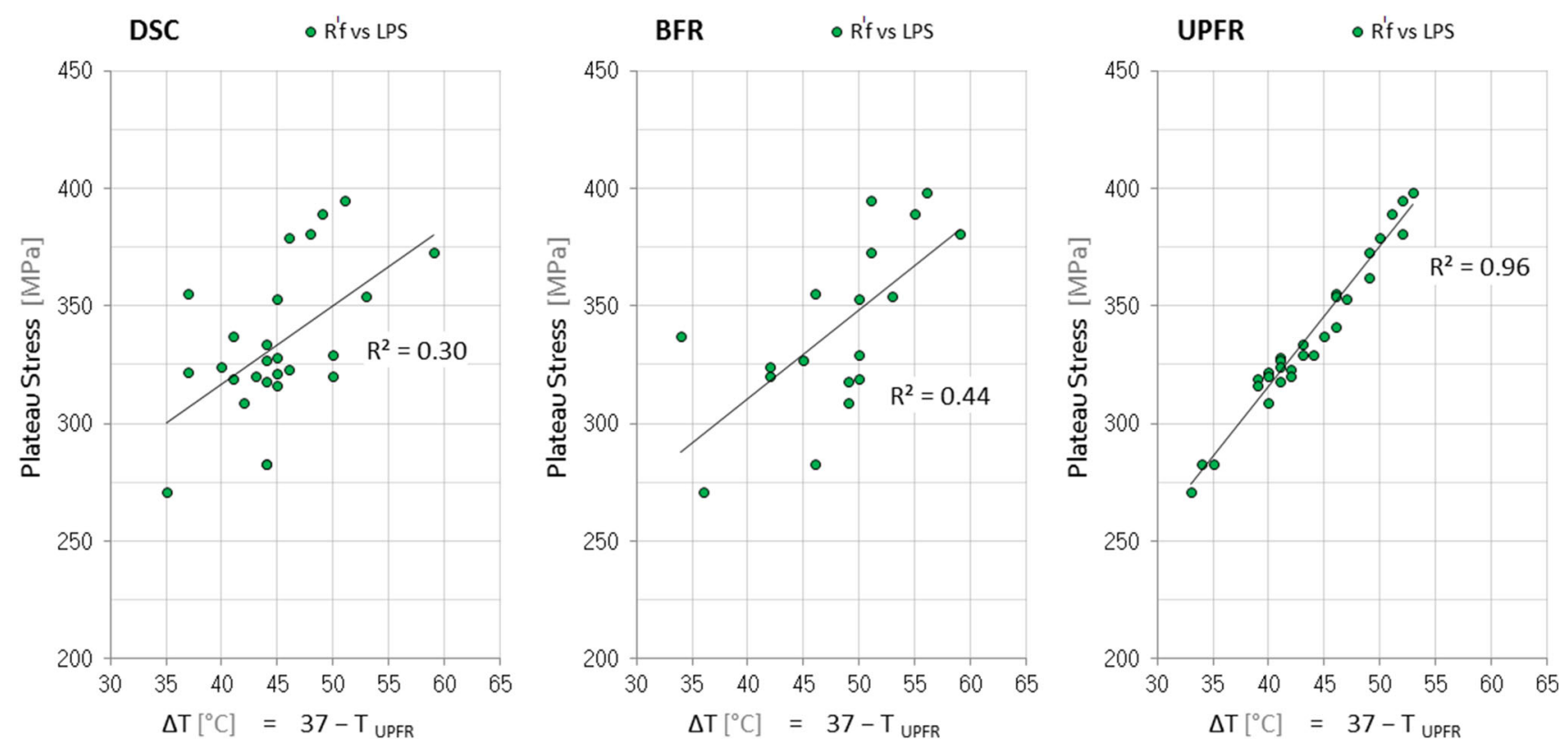

Fig. 6 Correlation between LPS measured at $37{ }^{\circ} \mathrm{C}$ via ASTM F2516 [8] and martensite reversion temperature $\left(R_{\mathrm{f}}^{\prime}\right)$ measured via (i) DSC, (ii) BFR, and (iii) UPFR. The Clausius-Clapeyron relation for this class of superelastic materials is thereby defined by the slope of the

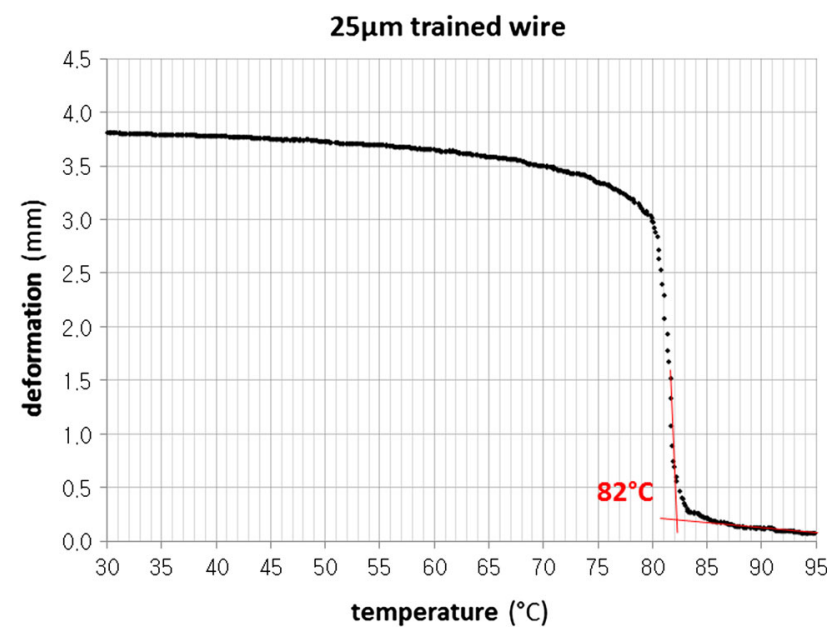

Fig. 7 Measure of phase transformation temperatures on a $25-\mu \mathrm{m}$ trained NiTi shape memory wire using UPFR

definitely weaker when temperatures are measured by BFR. As expected, results from DSC do not show good correlation with the LPS. Moreover, as pointed out by Duerig and Bhattacharya in a recent review [11], it must be noted that $R_{\mathrm{f}}^{\prime}$, and not $A_{\mathrm{f}}$, is the key parameter linked with martensite reversion in NiTi.

The data from Fig. 8 show the versatility of the instrument in handling different samples and the ease of measuring the transformation temperatures. For example, the phase transformation temperatures of fine drawn NiTi wires or a thin strip sample could be easily measured. In linear trendline. The related coefficient of determination, $R^{2}$, represents the goodness of the fit and defines the accuracy of the test method

the case of not axially aligned components like the NiTi/ $\mathrm{NiTiCu}$ shape memory springs and microsprings, the material is not experiencing an uniform state of stress due to rotation and shear stress. Nevertheless, UPFR can be used to observe the real response of those components along their working direction. Although the outcome of the test is not exclusively linked to material properties (as sample geometry plays a significant role), the interpretation of the test is very similar to the measurement of stent expansion recovery behavior through BFR. Further work is however needed to better exploit the potentiality of UPFR in rotating or shaped specimens.

Thus, from the above examples, UPFR is established as a versatile and sound technique for the determination of phase transformation temperatures in superelastic and shape memory NiTi products or components.

\section{Conclusions}

The measurement of phase transformation temperatures in NiTi shape memory and superelastic alloys by UPFR technique has been established. A general test procedure has been developed and it has been demonstrated the negligible effect of the applied pre-strain, as long as it does not induce plastic deformations. It has been found that small differences between the measured temperatures by BFR and UPFR are due to the higher sensitivity of the latter method as well as to differences in the state of 

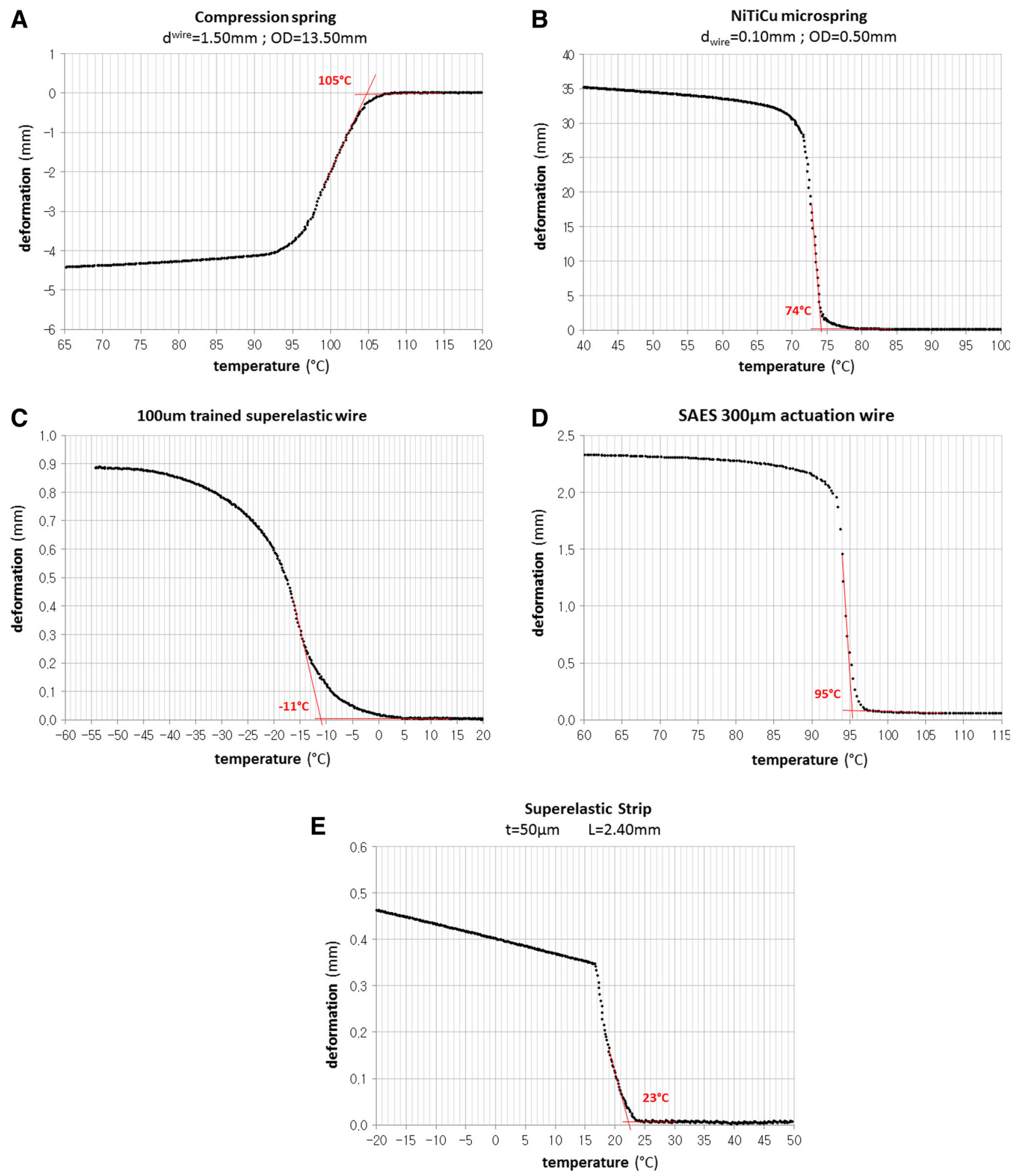

Fig. 8 Measurement of phase transformation temperatures, using UPFR, from various NiTi samples. Table 2 provides information on the geometry/size of the test sample used for these tests

induced stress. The sensitivity was evaluated through a systematic correlation among measured $R_{\mathrm{f}}^{\prime}$ temperatures and the thermo-mechanical behavior at $37^{\circ} \mathrm{C}$. A strong relation between $R_{\mathrm{f}}^{\prime}$ and LPS has been found. The successful and repeatable measurement of $A_{\mathrm{f}}$ temperature on $25 \mu \mathrm{m}$ shape memory wires demonstrates the usefulness of this technique at smaller product or component sizes. Further, the versatility of the technique was demonstrated 
by testing samples with different geometry, dimensions, composition, and functional properties. The achieved results validate the ease of using the UPFR technique in an industrial setting.

\section{References}

1. Standard test method for transformation temperature of NickelTitanium alloys by thermal analysis. ASTM F2004-05

2. Standard test method for determination of transformation temperature of Nickel-Titanium alloys by bend and free recovery. ASTM F2082-06

3. Zhang S, Denton M, Desai P, Licht G, Fariabi S (2004) Phase transition sequence and $A_{f}$ determination in Nickel-Titanium shape memory alloys. In: Proceedings of the international conference on shape memory and superelastic technologies, BadenBaden, pp 21-27

4. Nußkern H, Johe R (2004) Determination of the $A_{f}$ Temperature of NiTi Alloys per DSC and mechanical measurement methods. In: Proceedings of the international conference on shape memory and superelastic technologies. Baden-Baden, pp 307-312
5. Wu MH, Polinsky M, Webb N (2008) What is the big deal about $\mathrm{A}_{\mathrm{f}}$ temperature? In: Proceedings of the international conference on shape memory and superelastic technologies, Pacific Grove, pp 143-154

6. Hartl DJ, Mabe JH, Benafan O, Coda A, Conduit B, Padan R, Van Doren B (2009) Standardization of shape memory alloy test methods toward certification of aerospace applications. Smart Mater Struct. doi:10.1088/0964-1726/24/8/082001

7. Urbano M, Coda A, Giannantonio R (2006) SMAq: a novel integrated instrument for the characterization of SMA wires. In: Proceedings of the international conference on shape memory and superelastic technologies, Pacific Grove, pp 177-184

8. Drexel M, Proft J, Russel S (2009) Characterization of transformation temperatures with bend and free recovery technique: parameters and effects. J Mater Eng Perform 18:620-625

9. Coda A, Butera F, Vergani G, Fumagalli L, Toia L (2007) SmartFlex NiTi wires for shape memory actuators. In: Proceedings of the international conference on shape memory and superelastic technology, Tsukuba, pp 405-412

10. Standard test method for tension testing of Nickel-Titanium superelastic materials, ASTM F2516-14

11. Duerig TW, Bhattacharya K (2005) The influence of the R-phase on the superelastic behavior of NiTi. Shape Mem Superelasticity. doi:10.1007/s40830-015-0013-4 